\title{
Parametric Effects of Single Point Incremental Forming on Hardness of AA1100 Aluminium Alloy Sheets
}

\author{
Sherwan Mohammed Najm ${ }^{1,2, *(\mathbb{D})}$, Imre Paniti ${ }^{1,3} \mathbb{D}^{\mathbb{D}}$, Tomasz Trzepieciński ${ }^{4}\left(\mathbb{D}\right.$, Sami Ali Nama ${ }^{5}$, \\ Zsolt János Viharos ${ }^{3,6}$ and Adam Jacso ${ }^{1}$ (D)
}

1 Department of Manufacturing Science and Engineering, Budapest University of Technology and Economics, Múegyetem rkp 3, H-1111 Budapest, Hungary; imre.paniti@sztaki.hu (I.P.); jacso.adam@gpk.bme.hu (A.J.)

2 Kirkuk Technical Institute, Northern Technical University, Kirkuk 41001, Iraq

3 Centre of Excellence in Production Informatics and Control, Institute for Computer Science and Control (SZTAKI), Kende u. 13-17, H-1111 Budapest, Hungary; viharos.zsolt@sztaki.hu

4 Department of Manufacturing and Production Engineering, Faculty of Mechanical Engineering and Aeronautics, Rzeszow University of Technology, Al. Powst. Warszawy 8, 35-959 Rzeszów, Poland; tomtrz@prz.edu.pl

5 Engineering Technical College, Middle Technical University, Baghdad 10074, Iraq; drsami@mtu.edu.iq

6 Department of Management and Business Law, Faculty of Economics and Business, John von Neumann University, Izsáki Str. 10, H-6000 Kecskemét, Hungary

* Correspondence: sherwan.mohammed@gpk.bme.hu

Citation: Najm, S.M.; Paniti, I.; Trzepieciński, T.; Nama, S.A.; Viharos, Z.J.; Jacso, A. Parametric Effects of Single Point Incremental Forming on Hardness of AA1100 Aluminium Alloy Sheets. Materials 2021, 14, 7263. https://doi.org/10.3390/ma14237263

Academic Editors: Jie Zhou and Valentin Ştefan Oleksik

Received: 14 October 2021

Accepted: 17 November 2021

Published: 27 November 2021

Publisher's Note: MDPI stays neutral with regard to jurisdictional claims in published maps and institutional affiliations.

Copyright: (C) 2021 by the authors. Licensee MDPI, Basel, Switzerland. This article is an open access article distributed under the terms and conditions of the Creative Commons Attribution (CC BY) license (https:/ / creativecommons.org/licenses/by/ $4.0 /)$.

\begin{abstract}
When using a unique tool with different controlled path strategies in the absence of a punch and die, the local plastic deformation of a sheet is called Single Point Incremental Forming (SPIF). The lack of available knowledge regarding SPIF parameters and their effects on components has made the industry reluctant to embrace this technology. To make SPIF a significant industrial application and to convince the industry to use this technology, it is important to study mechanical properties and effective parameters prior to and after the forming process. Moreover, in order to produce a SPIF component with sufficient quality without defects, optimal process parameters should be selected. In this context, this paper offers insight into the effects of the forming tool diameter, coolant type, tool speed, and feed rates on the hardness of AA1100 aluminium alloy sheet material. Based on the research parameters, different regression equations were generated to calculate hardness. As opposed to the experimental approach, regression equations enable researchers to estimate hardness values relatively quickly and in a practicable way. The Relative Importance (RI) of SPIF parameters for expected hardness, determined with the partitioning weight method of an Artificial Neural Network (ANN), is also presented in the study. The analysis of the test results showed that hardness noticeably increased when tool speed increased. An increase in feed rate also led to an increase in hardness. In addition, the effects of various greases and coolant oil were studied using the same feed rates; when coolant oil was used, hardness increased, and when grease was applied, hardness decreased.
\end{abstract}

Keywords: SPIF; single point incremental forming; sheet forming; hardness; ANN; relative importance (RI)

\section{Introduction}

Incremental Sheet Forming (ISF) is a sheet-forming technique that produces components through a series of small incremental deformations. ISF is a flexible active manufacturing process and is economically feasible for low-volume production due to the absence of a punch and die. SPIF is one of the major types of ISF, and it is known as the simplest process variant of incremental sheet-forming technologies. SPIF is an emerging process that has been identified as suitable for use in small-scale production. Trzepieciński et al. [1] presented a brief overview of state-of-the-art methods of ISF for lightweight materials. The aim of their paper was to guide and inspire researchers by identifying current development trends of valuable contributions in the field of Single Point Incremental Forming (SPIF) of lightweight metallic materials. In SPIF, a rotating tool with a rounded tip at its end is used, 
and the desired shape is formed from clamped sheet metal [2]. In the literature [3], a review paper on new advances and future opportunities considered single point incremental to be one of the forming technologies of future-proof materials in aerospace applications. Furthermore, there is governmental, academic, and business interest in developing new manufacturing technologies, and there is also interest in ISF's impact on the environment, particularly in what ways and to what extent ISF reduces energy needs [4]. Two exergy analyses of traditional forming and hydroforming of ISF were contrasted by Dittrich et al. in [5]. After analysing the environmental impact of these forming techniques in the supply chain, they concluded that ISF is significantly less harmful to the environment, particularly for prototypes and non-mass production. Sustainability guidelines were developed by Ingarao et al. [6] regarding the advantages and disadvantages of SPIF related to the amount of energy necessary to form sheets and to economic material use in each process. Ingarao et al. proved that SPIF supports saving material with respect to $\mathrm{CO}_{2}$ emissions, because it supports recycling and facilitates novel ways of preparing raw materials. An overview of the history of ISF was written by Emmens et al. [7], Li et al. [8], and Behera et al. [9]: they discussed the enormous benefits and many advantages of SPIF and particularly referenced the flexibility of the process, which allows SPIF to be used in more applications in industries and processes. Hence, SPIF will be considered an essential process for the industry in the future.

By studying the mechanical properties of components formed through SPIF and standardising effective process parameters, the SPIF process can become a significant industrial application embraced by numerous companies. To set optimal input process parameters of SPIF with multiple pure copper sheets, Raju and Sathiya [10] utilised a hybrid optimisation technique by connecting it with Taguchi grey relational analysis and the methodology of the response surface. They showed that the feed rate is the most significant parameter, followed by step depth and tooltip diameter. On the other hand, lubrication plays a vital role in the successful forming of components during the SPIF process. Lubrication reduces friction at the contact zone of the tool and sheet [11]. Recently, José et al. [12] studied how mineral oil, sunflower, soybean, and corn lubricants influence friction and wear effects on aluminium parts manufactured using the SPIF process. Using a scanning electron microscope, they found the following: the experimental characterisation of the sample's surface showed that the worn surface of the metallic material samples produced using vegetable oils increases surface roughness compared to those produced with mineral oils. With respect to aluminium alloy foils, Najm and Paniti $[13,14]$ noted that a flat tool yielded better outcomes than a hemispherical tool in various conditions of the SPIF process. The best geometric accuracy was achieved when the smallest corner radius flat tool was used because a decrease in spring-back was observed. ISF-as-a-Service was introduced by Paniti [15], who distinguished first-order and second-order bottleneck parameters. He described the main capabilities of an incremental sheet-forming service provider in cloud manufacturing. The hardening and normal anisotropy coefficients are the most influential factors on traditional Forming Limit Diagrams (FLDs), as found by Fratini et al. [16] when studying the relationship between material formability and mechanical properties. On the other hand, Zhang [17] concluded that the most influential factor on formability is forming temperature, followed by vertical step depth, sheet thickness, and tooltip diameter. The above-mentioned results were obtained on $\mathrm{Mg}$ alloy sheets formed by using warm incremental sheet forming. Liu et al. [18] asserted that formability and maximum vertical force increase when vertical step-down increases, and they linearly increase when sheet thickness is increased. In their study [19], Li et al. found that mechanical properties and the thinning rate were affected by three parameters of ISF. It was shown that an increase in the tool diameter considerably improved the microhardness of the product's surface. An increase in the tool diameter and a decrease in the step size ultimately increase the tensile strength rate. Li et al. claimed that contrary to step size, sheet thickness significantly affects yield strength. In [20], Manco et al. proved that, due to variations in tool path, tool trajectory could be considered an essential parameter for the optimisation of process design 
by comparing the smallest thickness of the sheet with predicted thickness using the sine law. Krasowski et al. [21] analysed and discussed experimental investigations of the effects of selected SPIF parameters on the formability of DC04 sheets and the susceptibility to crack formation on truncated cones produced through SPIF, and they found that lubrication conditions clearly affect the formability of DC04 steel sheets.

At present, many methods of artificial intelligence are used in various applications, including the metal forming process. More specifically, ANN generates predictive models for end-milling machining, powder metallurgy, and high-speed machining [22-24]. Moreover, machine learning techniques with controlled manufacturing are used to develop various effective predictive models [25-29]. Trzepieciński et al. [30] presented an analysis of the interaction between SPIF process parameters and the main roughness parameters. They found that predictive models of ANNs for Ra and Rz were characterised by performance measures of $R^{2}$ values between 0.657 and 0.979 . In other studies, different tool materials and shapes were investigated experimentally to study factors including formability, geometric accuracy [31], and surface roughness [32] on an AlMn1Mg1 sheet formed using SPIF under various forming conditions. The researchers evaluated the performance of an Artificial Neural Network (ANN) and Support Vector Regression (SVR). Two different ANN models were built in the study: an R-squared value with other validation metrics and a feed-forward neural network with a backpropagation algorithm were used. A close correspondence was found between predicted roughness, formability, and geometric accuracy in the experimental results. The researchers derived regression equations to analytically predict surface roughness in terms of Ra and Rz. Baruah et al. [33] claimed that lubrication was the largest contributing factor in the process of ISF in all three directions (rolling, transverse, and angular) when surface roughness in ISF is meant to be reduced. In fact, to date, the applied lubricant and the viscosity of the lubricants on the ISF process have not been optimised or discussed, as attested by [5,34,35]. In addition, Kumar and Gulati [34] claimed that all parameters investigated in their study were significant for forming force except lubricating oil viscosity, and they also noted that surface roughness decreased when viscosity increased [35]. According to the literature, ANN is a helpful tool-before starting new experiments - for predicting and designing predictive models to estimate expected results, behaviour, or direction based on the use of the parameters of the studied process. Using ANN before starting an actual experiment has the essential benefits of selecting the correct parameters, reducing processing time, increasing efficiency, minimising errors, and comparing actual results with predicted ones so as to reach the best values. In addition, ANN is considered one of the most powerful tools for solving engineering problems by predicting experimental data. In addition, ANN can serve as a valuable means to generate and assess different processes and prepare the final details of tools.

Under normal conditions, the hardness behaviour in SPIF is as follows: formed parts achieve higher hardness than an unformed sheet. Using different path strategies and different forming angles, Al-Attaby et al. [36] showed that the tool path affects the hardness and microstructure of the formed sheet. In all cases relating to the forming angle, hardness increased. Regarding the two-point incremental forming process, Mostafanezhad et al. [37] analysed the formability of aluminium 1050: the scholars used the response surface methodology experimentally. They found that wall angle is the most influential factor with respect to the thinning ratio; initial thickness, followed by step-down, has a significant impact on forming force.

The above-detailed issues, the need for well-defined mechanical properties of SPIF components, and the lack of referent analytical models prompted the authors to investigate the effects of SPIF process variables on the hardness of truncated cones formed from AA1100 aluminium alloy sheets. Moreover, as a novelty and aim contributing to the significance of this paper, different regression equations were derived to determine the hardness of the components of a truncated cone using SPIF. In addition, the Relative Importance (RI) of parameters of SPIF on hardness was assessed and classified by utilising the joint partitioning weight of the built neural network. To the best of the authors' knowledge 
and according to the literature introduced, such an experimental process has not been reported to date. In this research, the influences of feed rate, various kinds of grease and coolant oil, spindle speed, and tool diameter on the hardness of the AA1100 aluminium alloy sheet formed by SPIF were investigated. Conventionally, AA1100 alloy is employed for radiator components [38]. However, as a final general aim, it was posited that the appropriate selection of properties would improve the application of the AA1100 alloy. Furthermore, based on the diver's mechanism of deformation, Song et al. [39] found three different regions of deformation (bending/stretching, shear, and stretch/shear). Based on these research projects, in this study, hardness was measured in three different positions on the inside wall of the cone, and measured data were compared to the primary hardness of the sheet involved in the experiment.

\section{Material and Methods}

\subsection{Workpiece Material}

Aluminium and aluminium alloys have become attractive materials for application in the aerospace and automotive industries owing to their beneficial properties. In the experiments conducted in this study, single point incremental forming tests were conducted using a blank sheet of AA1100 aluminium alloy were produced by Xuzhou Bozhan Aluminum Technology Co. Ltd, Xuzhou, Jiangsu, China with an initial hardness of $42.87 \mathrm{HV}$. The initial thickness of the sheet used is $0.6 \mathrm{~mm}$, with an original surface roughness of $0.29 \mu \mathrm{m}$. AA1100 aluminium belongs to the $1 \times x x$ series with less than $1 \%$ alloying elements. The main uses of the $1 \times x x$ series aluminium alloys are foil and strip for packaging, chemical equipment, tank car or truck bodies, spun hollowware, and elaborate sheet metal work because of their high corrosion resistance and formability [40]. The 1xxx alloys are essentially characterised by superior corrosion resistance, usefulness for fabricating chemical tanks and piping, or their excellent electrical conductivity, as in bus bar applications. These alloys have relatively poor mechanical properties [41].

If strength is not an essential factor, AA1100 aluminium is selected to create fuel tanks, cowlings, and oil tanks of aircraft due to the corrosion resistance and the economic weight. The before-mentioned grade of aluminium can be utilised to repair aircraft wingtips and tanks because it is weldable [42]. AA1100 commercially pure aluminium is highly resistant to chemical attack and weathering. This low-cost material is characterised by excellent solderability and susceptibility to deep drawing. It is used for high-purity applications such as chemical processing equipment. In addition, examples of common 1xxx series aluminium alloy applications include nameplates, fan blades, flue lining, sheet metal work, spun holloware, and fin stock [43]. It is also used to produce decorative parts, giftware, cooking utensils, rivets, and reflectors. A SPECTROMAXx optical emission spectrometer manufactured by SPECTRO, Kleve, Germany was used to determine the chemical composition of the AA1100 alloy used, and the test of mechanical properties was conducted with a United testing machine according to the ASTM B557M-15 standard test methods for tension check. The results of the tests of the aluminium sheet were compared with the nominal values in the ASM Handbook [44]: these tests show the conformity to the standard composition of the alloy (ISO 19000 standard). The mechanical properties and the chemical composition of the sheet material are shown in Tables 1 and 2, respectively.

Table 1. Mechanical properties of the AA1100 aluminium alloy sheet.

\begin{tabular}{cccc}
\hline Property & $\begin{array}{c}\text { Ultimate Tensile } \\
\text { Stress, } \mathbf{M P a}\end{array}$ & Yield Strength, MPa & Elongation, \% \\
\hline Actual & 110 & 95 & 20 \\
Nominal & 110 & 103 & 25 \\
Standard Deviation, $\sigma$ & 0 & 4 & 2.5 \\
\hline
\end{tabular}


Table 2. Chemical composition of the AA1100 aluminium alloy sheet (in wt.\%).

\begin{tabular}{ccccccccccccccc}
\hline Element & $\mathbf{S i}$ & $\mathbf{F e}$ & $\mathbf{C u}$ & $\mathbf{M n}$ & $\mathbf{M g}$ & $\mathbf{C r}$ & $\mathbf{N i}$ & $\mathbf{Z n}$ & $\mathbf{T i}$ & $\mathbf{P b}$ & $\mathbf{B}$ & $\mathbf{S n}$ & $\mathbf{V}$ & $\mathbf{A l}$ \\
\hline Actual & 0.110 & 0.482 & 0.004 & 0.005 & 0.001 & 0.0005 & 0.004 & 0.021 & 0.021 & 0.0005 & 0.003 & 0.001 & 0.014 & balance \\
Nominal & 0.5 & 0.5 & 0.2 & 0.04 & 0.01 & & & & Other 0.15 max & & & & balance \\
\hline
\end{tabular}

\subsection{Experimental Setup}

In this study, a Boxford 300VMCi milling machine built by Boxford in Halifax, UK with $0.01 \mathrm{~mm}$ accuracy was used. The ISO format using $\mathrm{G}$ and $\mathrm{M}$ codes was used to program a cone shape with large and small diameters of 80 and $10 \mathrm{~mm}$, respectively. An inward spiral path strategy was used to deform the cone part, in which case a spiral tool trajectory is advantageous to the successful forming of the same parts [45]. The strategy utilised in this study was developed by Skjoedt et al. [46] to overcome the difficulty of reaching maximum axial loads at each layer (step down) and to prevent the appearance of a line on the inner side of the formed part. A wall angle of $45^{\circ}$, a context contour of $0.5 \mathrm{~mm}$ for the step size, and an inward spiral path were applied, as shown in Figure 1.

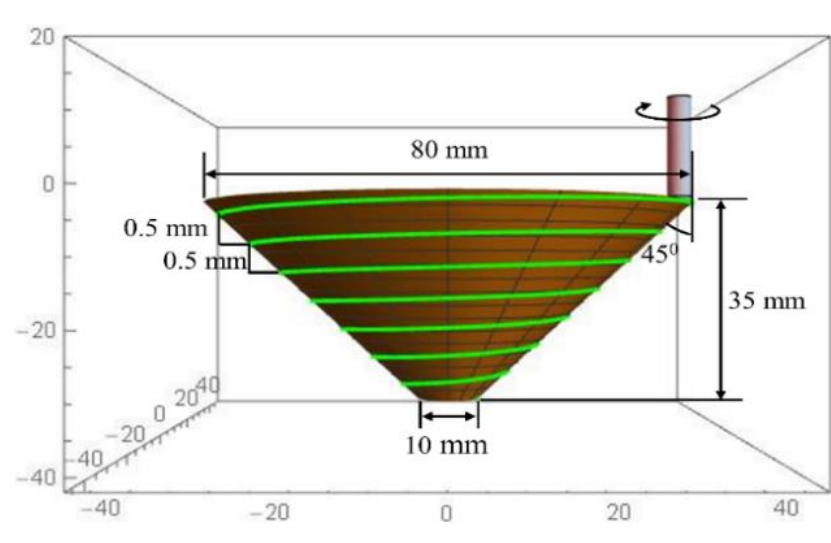

(a)

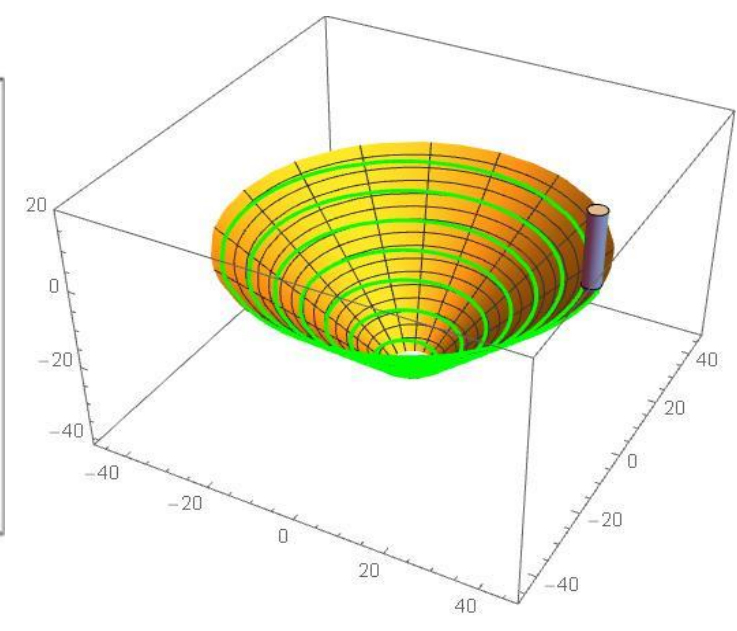

(b)

Figure 1. (a) CAD geometry and dimensions of the experimental product and (b) view of an inward spiral path.

In the SPIF process, only one tool can be used, and the feed rate, spindle speed, lubricant, and forming conditions should be selected beforehand. Furthermore, in the current study, the mentioned parameters were considered parametric values and were changed in the subsequent part forming. A primary step was conducted to select the best values of these parameters to fix them in the subsequent forming process, and only one of these parameters was changed in each forming group. To this end, a matrix of 3 factors with the same levels (feed rate, spindle speed, and tool diameter) was applied in the first step. The best values of feed rate, spindle speed, and tool diameter were chosen depending on the best geometrical accuracy and maximum depth. In the second step, the best values selected from the first step were applied in order to study the coolant type.

Forming tools with different diameters $(4,6,8$, and $10 \mathrm{~mm})$ were used in the experiment, as shown in Figure 2a. The tools used in the experiment are made of carbon steel with a hardness of $30 \mathrm{HRC}$ and are $100 \mathrm{~mm}$ in total length. Plain carbon steel was used for manufacturing the clamping rig, which was fixed to the CNC machine table with a simple-to-use fixture system, as shown in Figure $2 b$.

A digital Vickers microhardness tester supplied by TIME Group Inc., Beijing, China was used to measure the hardness of the component formed using SPIF (see Figure 3a) based on Equation (1). For each set, three products were experimentally formed to study the process parameters of different forming conditions (see Figure $3 b$ ). The hardness of 
each part was measured at three zones: the upper, middle, and lower zones along the inner wall of the formed part. Figure $3 c$ shows a formed part after it was cut to the desired shape in the proper size for the preparation of the test samples and for establishing the three zones of the hardness measurement. The hardness measurement was repeated three times at different points inside each mentioned zone. The hardness value of each zone was calculated as the average value of the selected zone hardness. The average hardness value of the three zones was considered the average value of the measured component. The appropriate piece of the section was mounted by a mounting press device and polished by a Metaserv type 250/RP device manufactured in (Buehler, Lake Bluff, IL, USA) before hardness was measured (see Figure 3d).

$$
H_{v}=1854.4 \frac{F}{d^{2}}
$$

where $F$ is penetration force $(\mathrm{N})$, and $d$ is average diagonal distance $(\mathrm{d} 1+\mathrm{d} 2) / 2$.

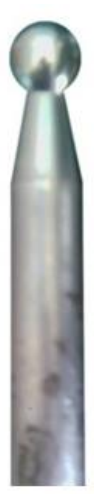

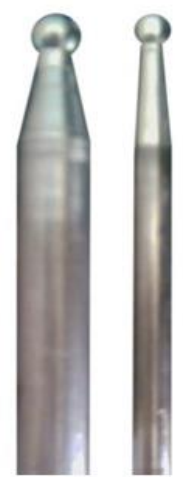

(a)
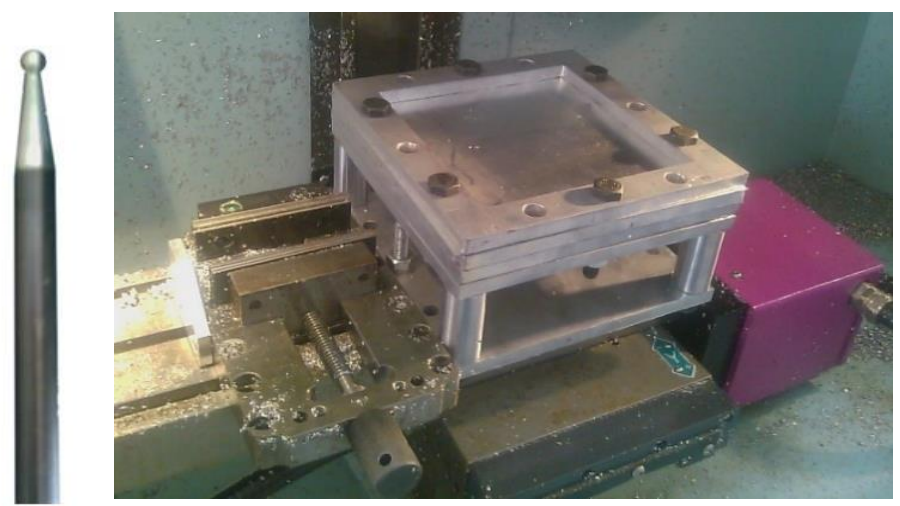

(b)

Figure 2. (a) Forming tools with different diameters, (b) fixture rig on the CNC machine table.
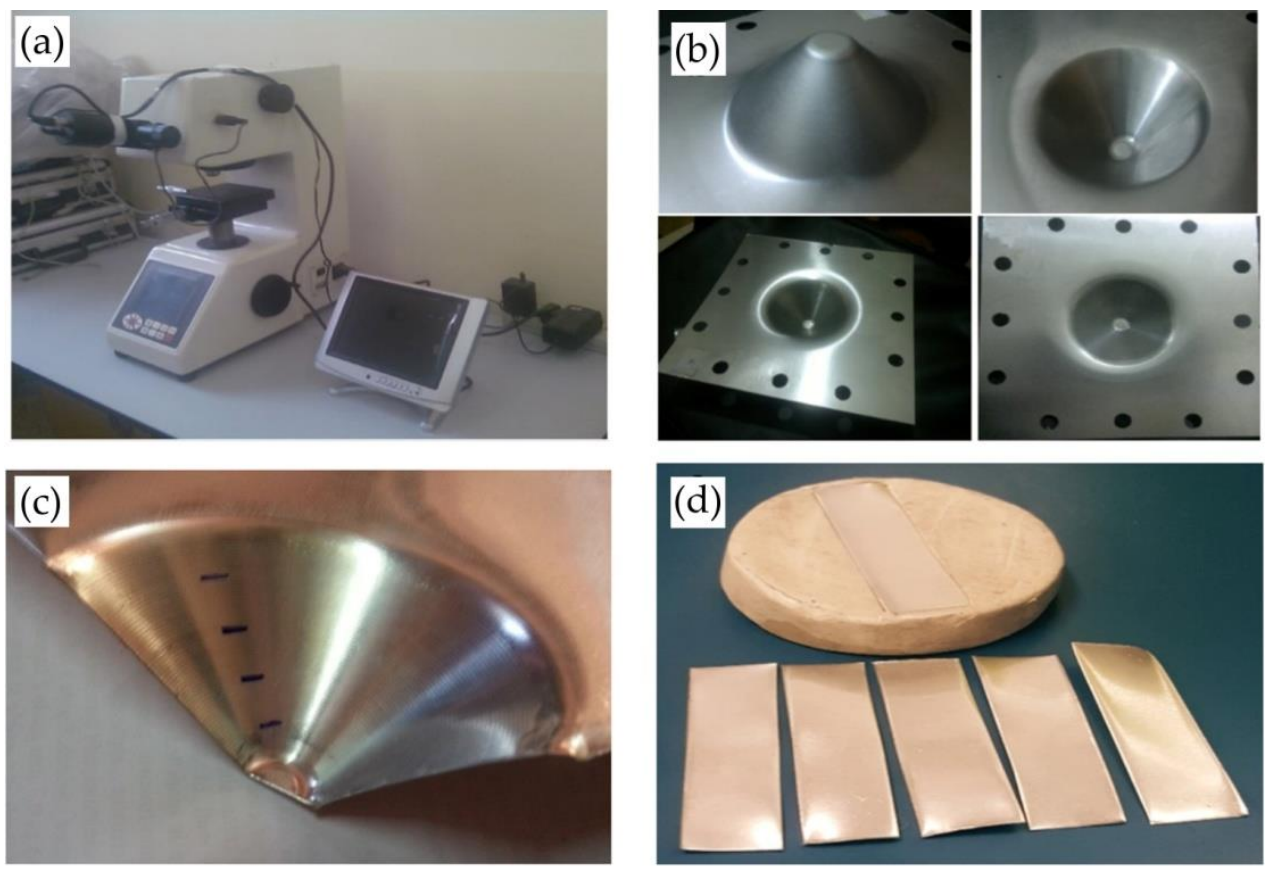

Figure 3. (a) Digital microhardness device, (b) formed parts, (c) three zones of hardness measurement, (d) hardness test sample of the formed part. 
For hardness measurement, the hardness tester was calibrated before testing using the calibration standard block, and $100 \mathrm{~N}$ was applied on the formed part with a Vickers diamond pyramid indenter for $15 \mathrm{~s}$. The results were recorded automatically on a digital screen after the adjustment of the rhomb corner had been triggered by the indenter.

There is no internationally accepted term for the definition of Environmentally Acceptable Lubricants (EALs), and they still lack standardisation. The American Society for Testing and Materials (ASTM) used "environmentally acceptable" as a phrase for defining EALs [47]. There is an overall trend towards using EALs. In the present study, different coolant types (four different grease types, as shown in Figure 4a-d, and one coolant oil) were used to carry out the experiment. Supergrees EP2 and Kaucuklu grease produced by Petrol Ofisi, Istanbul, Turkey, Zinol grease from Universal Lubricants (ZINOL) L.L.C, Sharjah, United Arab Emirates, Gp Grease Calcium type was produced by United Grease \& Lubricants Co. LLC based in Ajman, United Arab Emirates, and the coolant oil was also by Petrol Ofisi, Istanbul, Turkey. Table 3 lists grease properties based on their commercial name and standard denominations, and Table 4 presents coolant oil properties. It is worth mentioning that viscosity values of different greases were assumed based on the ISO 3448:1992 standard for viscosity grading systems [48].
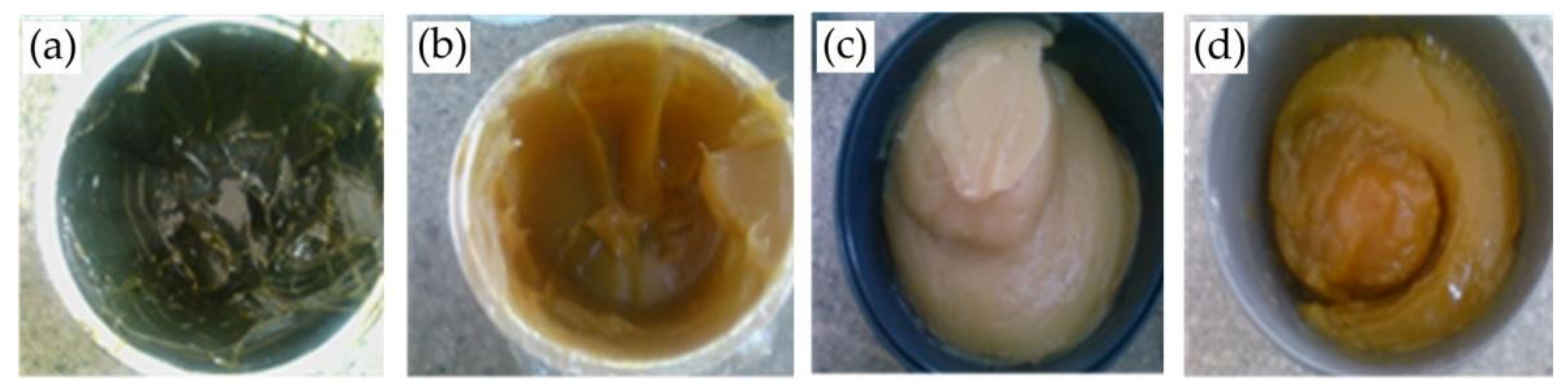

Figure 4. Different types of grease: (a) EP2, (b) Kaucuklu, (c) Zinol, (d) Gp Grease Calcium.

Table 3. Selected properties of the greases used.

\begin{tabular}{ccccc}
\hline Grease Type & ISO Viscosity Grade & $\begin{array}{c}\text { Average Dropping Point, }{ }^{\circ} \mathbf{C} \\
\left.\text { (at 25 }{ }^{\circ} \mathbf{C}\right)\end{array}$ & Flash Point, ${ }^{\circ} \mathbf{C}$ & $\begin{array}{c}\text { Viscosity at 40 }{ }^{\circ} \mathbf{C}, \\
\mathbf{m m}^{2} / \mathbf{s}\end{array}$ \\
\hline EP2 & ISO VG 15 & 90 & 180 & 15 \\
Kaucuklu & ISO VG 22 & 88 & 172 & 22 \\
Zinol & ISO VG 32 & 88 & 170 & 32 \\
Gp Grease Calcium & ISO VG 46 & 58 & 60 & 46 \\
\hline
\end{tabular}

Table 4. Selected properties of the coolant oil used.

\begin{tabular}{ccc}
\hline Acidity, pH & Kinematic Viscosity at $\mathbf{2 9}{ }^{\circ} \mathbf{C}, \mathbf{~ m m}^{2} / \mathbf{s}$ & Boiling Point, ${ }^{\circ} \mathbf{C}$ \\
\hline 1.086 & 1.086 & 95 \\
\hline
\end{tabular}

Lubricants cannot be used in forming processes where high loads are applied, and thus, Syahrullail et al. [49] suggested using an appropriate additive to solve this problem. Consequently, the difference between using coolant oil and grease is that grease forms a mixture with small disintegrating particles (debris) of either the formed sheet or, in rare cases, the tool. Due to heat generation, sometimes the debris repeatedly sticks to the sheet surface or passes between the tool and the formed sheet. Diabb et al. [50] observed aluminium flakes in the used lubricant: this phenomenon was caused by wear adhesion on alloy sheets of SPIF components. In the case of coolant oil, which flows continuously on the sheet, debris can be washed away from the forming zone. However, when grease is used, a smoother surface can be produced compared to the scenario where coolant oil is used due to the flattening and roughening effects exerted by the debris, as stated in [51]. 
On the other hand, coolant oil continuously flows during the forming process, whereas grease is applied on the sheet surface only once at the beginning of the process. In other words, coolant oil has higher exergy than grease due to the difference in the amount of material used, which means that an increased environmental impact is observable. Figure $5 \mathrm{a}, \mathrm{b}$ illustrate the processes of using grease and coolant oil.

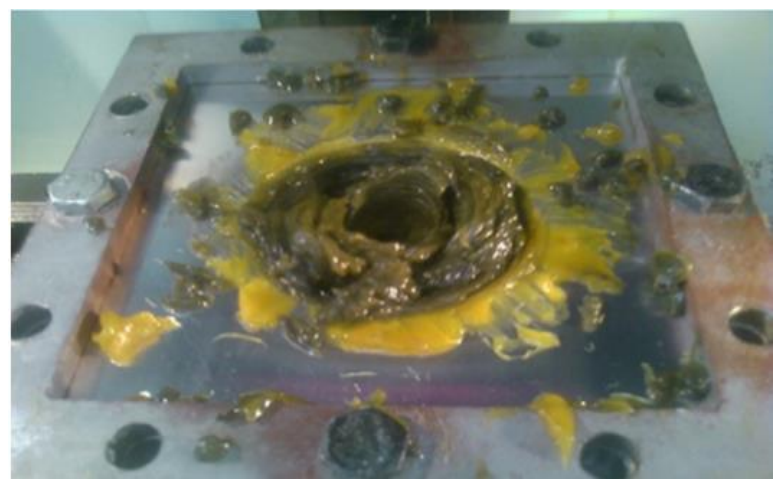

(a)

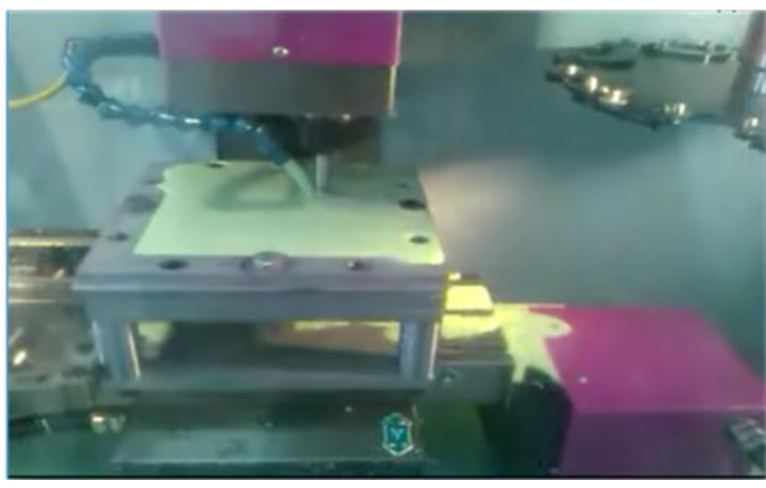

(b)

Figure 5. (a) Forming process using grease, (b) forming process using coolant oil.

Four different tool rotation speeds $(500,1000,1500$, and $2000 \mathrm{rpm})$ were used to study hardness behaviour. In addition, in the scope of the current experiments, four different feed rates $(200,400,600$, and $800 \mathrm{~mm} / \mathrm{min})$ were implemented to investigate the effects of changes in the feed rate on sheet hardness.

\section{Results and Discussion}

\subsection{Feed Rate}

Four different feed rates were used with different lubricants (oil and grease). At the same time, other experimental parameters were fixed: the tool speed was $2000 \mathrm{rpm}$, the tool diameter was $10 \mathrm{~mm}$, and coolant oil was used. Table 5 and Figure $6 \mathrm{a}, \mathrm{b}$ show the results of hardness measurements for different feed rates. Changing the lubricant type resulted in inverse values of hardness: it increased when the feed rate was increased and coolant oil was used, and it decreased when grease was used.

An increase in feed rate led to an increase in hardness, and this was inversely proportional to formability. The increase in feed rate caused a decrease in formability, as mentioned in [52]. A decrease in hardness is due to changes in surface asperities because the peaks of the aspirates formed by the generated debris shoot and break. By attaching the debris to the tool and cultivating the sheet surface, new grooves can be created, and the sharp peaks of the asperities can likewise be crashed. Finally, through continuous cultivation and crashing, the contact area between the tool and the formed sheet will increase.

Table 5. Effects of different feed rates on hardness.

\begin{tabular}{ccccccccc}
\hline & \multicolumn{9}{c}{ Hardness HV } \\
\cline { 2 - 9 } $\begin{array}{c}\text { Feed Rate, } \\
\text { mm/min }\end{array}$ & Top & Middle & Bottom & $\begin{array}{c}\text { Standard } \\
\text { Deviation, } \boldsymbol{\sigma}\end{array}$ & Top & Middle & Gottom & $\begin{array}{c}\text { Standard } \\
\text { Deviation, } \boldsymbol{\sigma}\end{array}$ \\
\cline { 2 - 9 } & 43.89 & 40.40 & 39.02 & 2.0494 & 63.30 & 58.61 & 50.56 & 5.2610 \\
\hline 200 & 39.16 & 43.61 & 41.78 & 1.8262 & 59.80 & 56.70 & 49.13 & 4.4816 \\
400 & 44.08 & 46.44 & 48.22 & 1.6957 & 51.29 & 53.17 & 44.70 & 3.6317 \\
600 & 47.76 & 53.84 & 49.54 & 2.5522 & 43.99 & 45.72 & 45.50 & 0.7689 \\
800 & & &
\end{tabular}


$\mathbf{a}$
- Average of Top Point Hardness
$\neg$ Average of Middle Point Hardness
- - Average of Bottom Point Hardness
- - - Average of Sheet Hardness

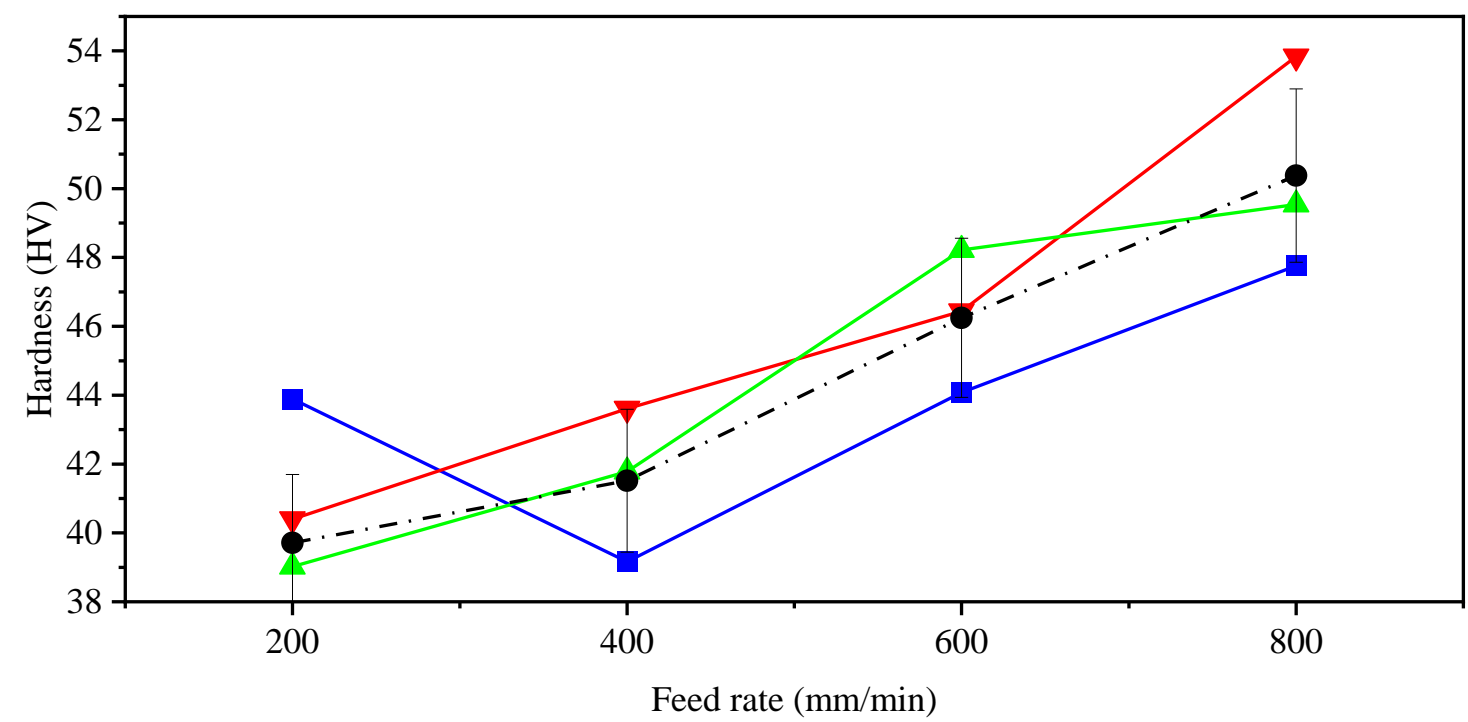

b
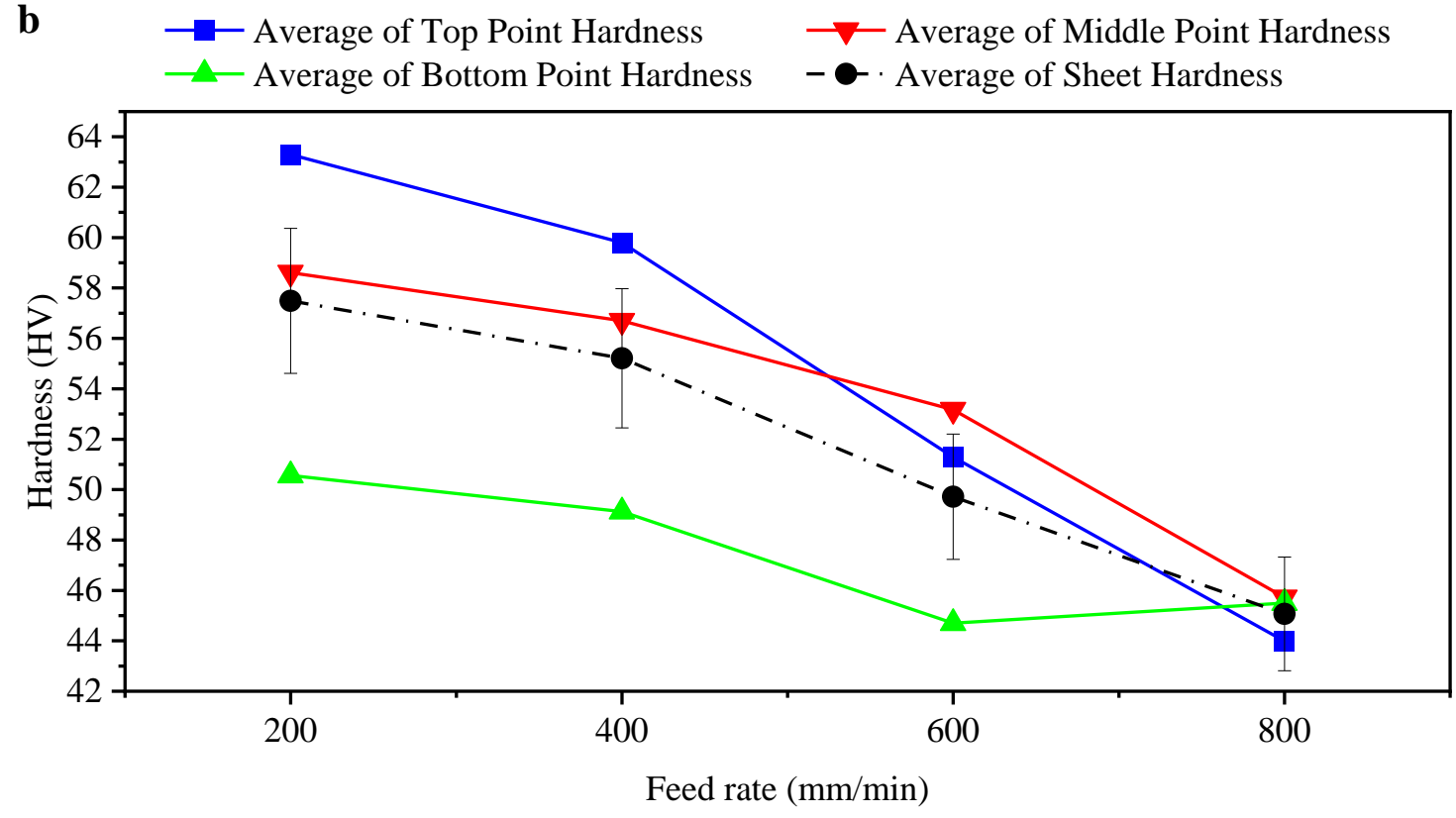

Figure 6. (a) Effects of different feed rates on hardness of formed sheet when using coolant oil, (b) effects of varied feed rates on hardness of formed sheet when using grease.

Hol et al. [53] mentioned that, in the case of normal forces, the sheet surface asperities are in the plastic condition, and they are further affected by only a little stress in the underlying bulk material. They claim that this stress is perpendicular to the normal force and generates increased plastic deformation of asperities. Finally, because of the enormous strain of the underlying material, this situation leads to an increased contact area, which is recognised as a decrease in effective hardness.

\subsection{Tool Speed}

Table 6 lists different tool rotation speeds with the experimentally obtained hardness values. Figure 7 shows that an increase in tool speed led to an increase in hardness. High speed causes the resulting particles to impact the surface of the sheet faster than in the case of low speeds, and this results in the hardening of the surface. On the other hand, in the case of high tool speeds, the tool head, in the same contact area, travels on the sheet with 
more passes than a tool at low speeds. Due to stretching with longitudinal deformation, the sheet material seems to be undergoing cold working conditions. Cold working creates a different type of crystal deformation, such as compressing, twisting, and bending, and this results in comparatively uniform plain crystalline particles. New imperfections created by these movements result in more resistance and, finally, increase hardness.

Table 6. Effect of different speed values on hardness.

\begin{tabular}{ccccc}
\hline \multirow{2}{*}{ Tool Speed, rpm } & \multicolumn{4}{c}{ Hardness HV } \\
\cline { 2 - 4 } & Top & Middle & Bottom & $\begin{array}{c}\text { Standard } \\
\text { Deviation, } \boldsymbol{\sigma}\end{array}$ \\
\hline 500 & 45.83 & 41.78 & 40.10 & 2.4050 \\
1000 & 50.50 & 47.48 & 42.75 & 3.1895 \\
1500 & 56.83 & 55.96 & 45.90 & 4.9601 \\
2000 & 61.58 & 75.51 & 57.71 & 7.6439 \\
\hline
\end{tabular}

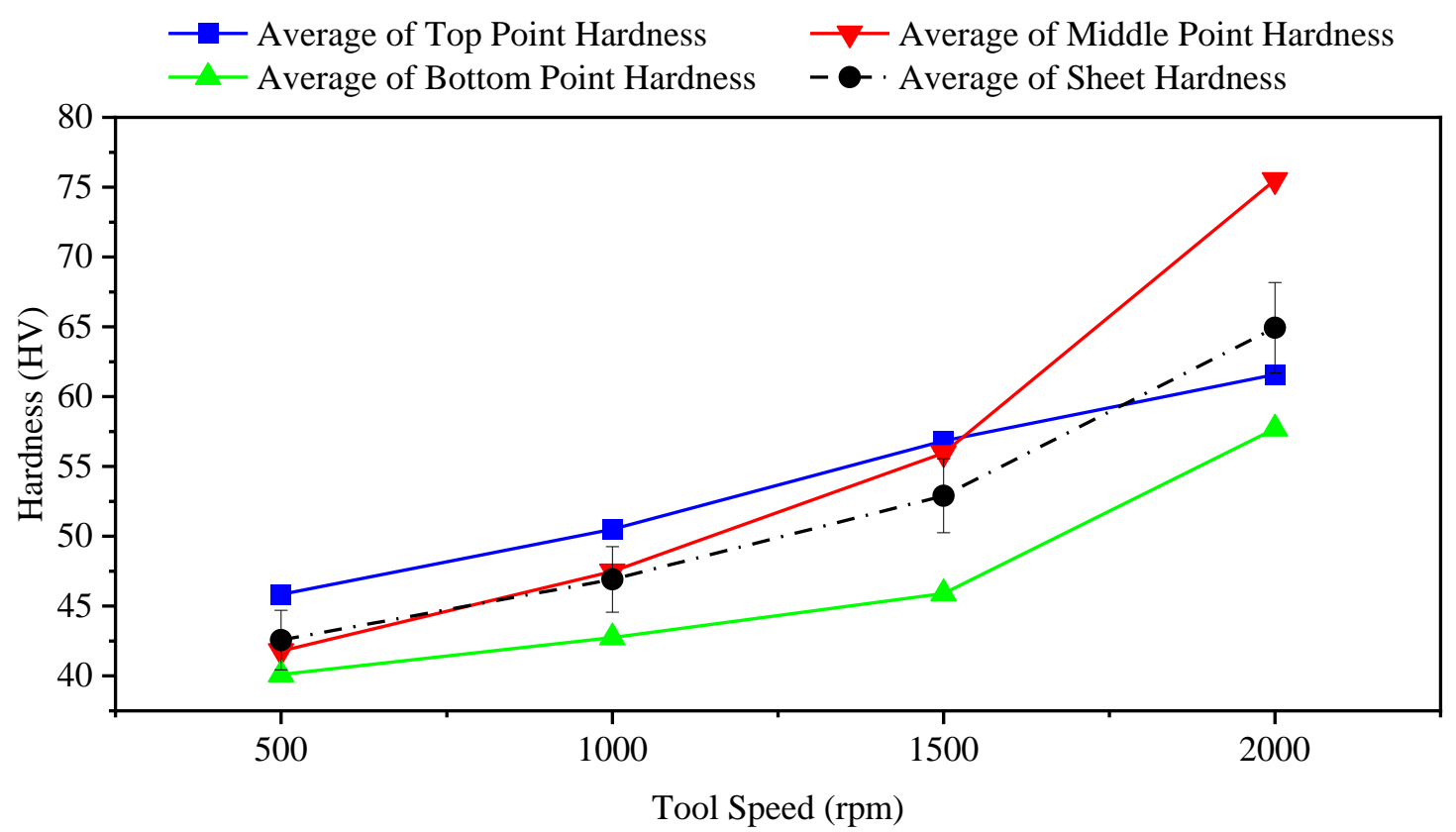

Figure 7. Effect of different tool speeds on hardness of formed sheet (feed rate: $600 \mathrm{~mm} / \mathrm{min}$; tool diameter: $10 \mathrm{~mm}$; coolant: oil).

\subsection{Tool Diameter}

The effects of tool diameter on hardness are presented in Table 7 and in Figure 8. Decreases in values are due to increases in tool diameter. McAnulty et al. [54] found different behaviours for the effects of changes in tool diameter on formability. Asgari et al. [55] concluded that a tool diameter of $3 \mathrm{~mm}$ results in increased hardness in an aluminium alloy 1100-O sheet relative to 5 or $10 \mathrm{~mm}$ tool diameters. A decrease in tool diameter from 10 to $3 \mathrm{~mm}$ causes ultimate tensile stress and yield stress to decrease by $7 \%$ and $24 \%$, respectively. Furthermore, a reduction in the tool diameter causes a decrease in grain size [55]. Shrivastava and Tandon [56] discussed various parameters of the pre-production sheet and studied the effects of such parameters on the ISF process and on the final properties of products. They claimed that the forces needed to form the sheet in ISF are affected by grain size. Increasing the grain size leads to a decrease in forming forces, yield stress, and hardness [56]. The researchers used different tools for forming, and all of the formed parts showed decreased hardness irrespective of the diameter of the applied tools. The results of this study show that hardness decreased in the case of any diameter of the tool irrespective of the hardness value at each point. A tool diameter of $4 \mathrm{~mm}$ showed higher hardness than 
other diameters at all points. Tool diameters of 10 and $8 \mathrm{~mm}$, on the other hand, produced lower hardness values than tool diameters of 6 and $4 \mathrm{~mm}$. In addition, larger tools, which passed through the formed sheet more times than smaller tools, made the material of the formed part softer (and also caused more heating through increased friction).

Table 7. Effects of different tool diameters on hardness.

\begin{tabular}{ccccc}
\hline \multirow{2}{*}{ Tool Diameter, mm } & \multicolumn{4}{c}{ Hardness HV } \\
\cline { 2 - 4 } & Top & Middle & Bottom & $\begin{array}{c}\text { Standard } \\
\text { Deviation, } \boldsymbol{\sigma}\end{array}$ \\
\hline 4 & 75.51 & 57.71 & 66.61 & 7.2668 \\
6 & 56.33 & 50.65 & 53.01 & 2.3299 \\
8 & 43.22 & 40.62 & 44.26 & 1.5308 \\
10 & 41.78 & 40.10 & 42.57 & 1.0300 \\
\hline
\end{tabular}

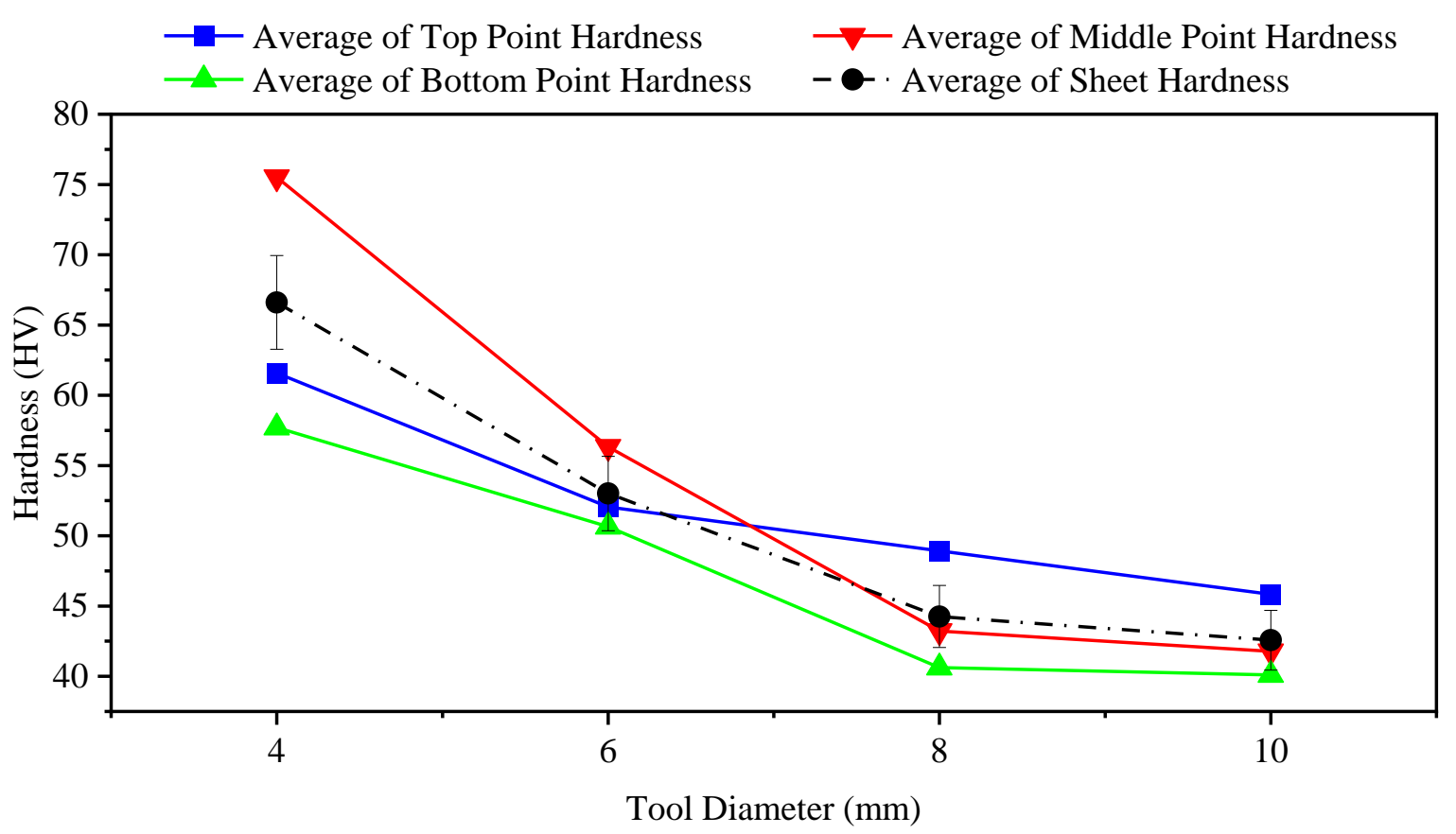

Figure 8. Effect of different tool diameters on hardness of formed sheet (feed rate: $600 \mathrm{~mm} / \mathrm{min}$; tool speed: $2000 \mathrm{rpm}$; coolant: oil).

\subsection{Grease Grade}

Table 8 and Figure 9 show the impact of different greases on the hardness results. The grease with the highest drop point resulted in the lowest hardness and vice versa. The grease type named "Gp Grease Calcium-ISO VG 46" provided the highest hardness (with the lowest drop point): this was due to the fact that this grease entered between the tool and the formed sheet and cooled the local forming zone faster. Regarding the properties of different greases, it is shown that the use of the grease with a higher flash point resulted in a more stable hardness value. In fact, it can be noted that the use of grease rather than the use of coolant oil produced more homogeneous hardness values at different points of the same sheet, with a slight difference in this conclusion for coolant oil compared to Gp Grease Calcium type grease.

\subsection{Regression Equations to Calculate the Hardness of SPIF Components}

Regression enables one to find an alternative method to quickly and more economically calculate SPIF components' hardness, rather than having to resort to an experimental process. In view of this, in our experiments, regression equations capable of calculating 
the hardness of SPIF were used instead of actual measurements. Consequently, different equations were used in this study: Equation (2) Linear Cross-Validation Regression, (3) Linear Cross-Validation with Multiple Regression of Viscosity, (4) Multiple Regression, and (5) Equation Based on Biases and Weight. These equations are as follows:

Table 8. Effects of different grease types on hardness.

\begin{tabular}{|c|c|c|c|c|c|c|c|}
\hline \multirow[b]{2}{*}{ Grease Type } & \multirow{2}{*}{$\begin{array}{c}\text { ISO } \\
\text { Viscosity Grade }\end{array}$} & \multirow[b]{2}{*}{$\begin{array}{c}\text { Average Dropping Point } \\
\left.\text { (at } 25^{\circ} \mathrm{C}\right)\end{array}$} & \multirow[b]{2}{*}{ Flash Point, ${ }^{\circ} \mathrm{C}$} & \multicolumn{4}{|c|}{ Hardness HV } \\
\hline & & & & Top & Middle & Bottom & $\begin{array}{c}\text { Standard } \\
\text { Deviation, } \sigma\end{array}$ \\
\hline Gp Grease Calcium & ISO VG 15 & 58 & 60 & 46.81 & 72.00 & 56.95 & 10.3487 \\
\hline Zinol & ISO VG 22 & 88 & 170 & 46.34 & 42.70 & 40.74 & 2.3202 \\
\hline Kaucuklu & ISO VG 32 & 88 & 172 & 42.73 & 38.12 & 40.62 & 1.8843 \\
\hline EP2 & ISO VG 46 & 90 & 180 & 45.81 & 43.30 & 38.18 & 3.1751 \\
\hline
\end{tabular}

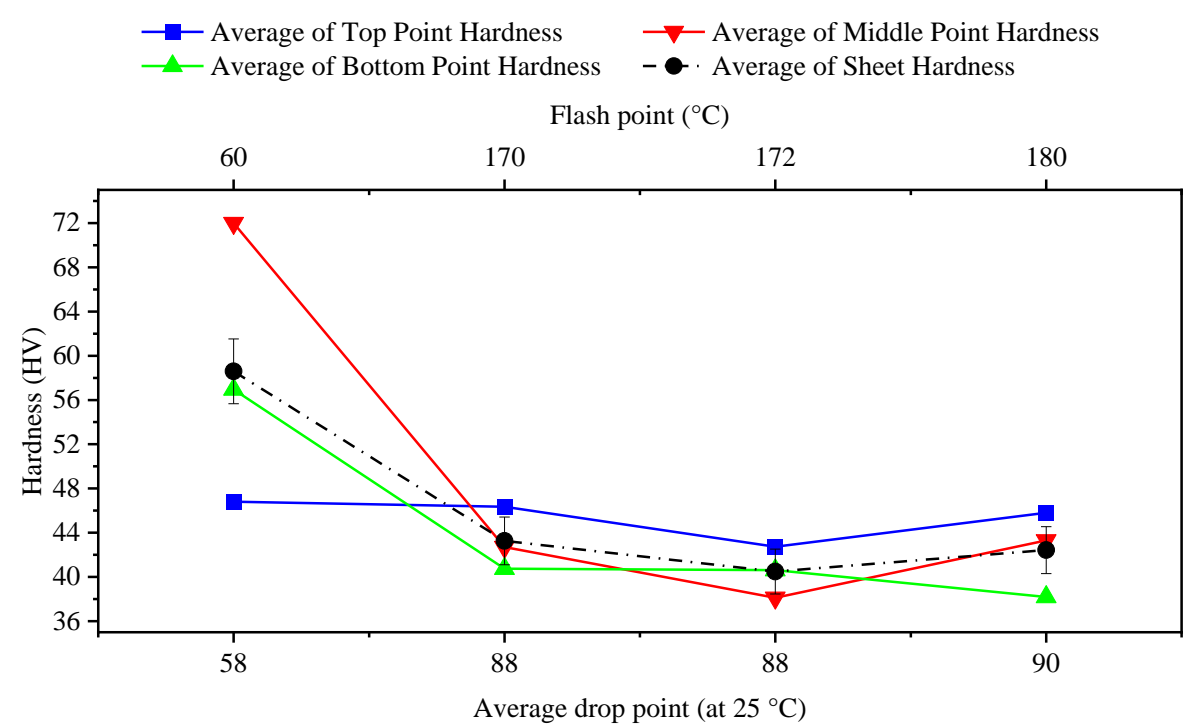

Figure 9. Effects of different grease types on hardness of formed sheet (feed rate: $600 \mathrm{~mm} / \mathrm{min}$; tool speed: $2000 \mathrm{rpm}$; tool diameter: $10 \mathrm{~mm}$ ).

Linear Cross-Validation Regression:

$$
\begin{gathered}
H=\left(F r_{\text {Coeff }} \times F r+S_{\text {Coeff }} \times S+D_{\text {Coeff }} \times D+L_{\text {Coeff }} \times L_{v}+C\right) / 4 \\
H=\left(0.0658 \times F r+0.0028 \times S-9.3993 \times D+0.2829 \times L_{v}+234.7775\right) / 4
\end{gathered}
$$

Linear Cross-Validation with Multiple Regression of Viscosity:

$$
\begin{gathered}
H=\left(F r_{\text {Coeff }} \times F r+S_{\text {Coeff }} \times S+D_{\text {Coeff }} \times D+\left(L_{\text {Coeff } 1} \times L_{v}-L_{\text {Coeff } 2} \times L_{v}^{2}\right)+C\right) / 4 \\
H=\left(0.0749 \times F r+0.007482 \times S-8.2277 \times D+\left(3.5691 \times L_{v}-0.0950 \times L_{v}^{2}\right)+217.7624\right) / 4
\end{gathered}
$$

Multiple Regression:

$$
\begin{aligned}
H=\left(F r_{\text {Coeff } 1} \times\right. & \left.F r-F r_{\text {Coeff } 2} \times F r^{2}\right)+\left(S_{\text {Coeff } 1} \times S-S_{\text {Coeff } 2} \times S^{2}\right) \\
& +\left(D_{\text {Coeff } 1} \times D^{2}-D_{\text {Coeff } 2} \times D\right)+\left(L_{\text {Coeff } 1} \times L_{v}^{2}\right. \\
& \left.-L_{\text {Coeff } 2} \times L_{v}\right)+C \\
H=(0.029255 \times & \left.F r-0.000010 \times F r^{2}\right)+\left(0.0278 \times S-0.000009 \times S^{2}\right) \\
& -\left(17.4122 \times D-1.0414 \times D^{2}\right) \\
& -\left(0.9343 \times L_{v}-0.0244 \times L_{v}^{2}\right)+87.4763
\end{aligned}
$$

Equation Based on Biases and Weights: 


$$
\begin{aligned}
& H=b_{2}+L W \times \operatorname{Exp}^{\left(-\left(b_{1}+I W \times x\right)^{2}\right)}
\end{aligned}
$$

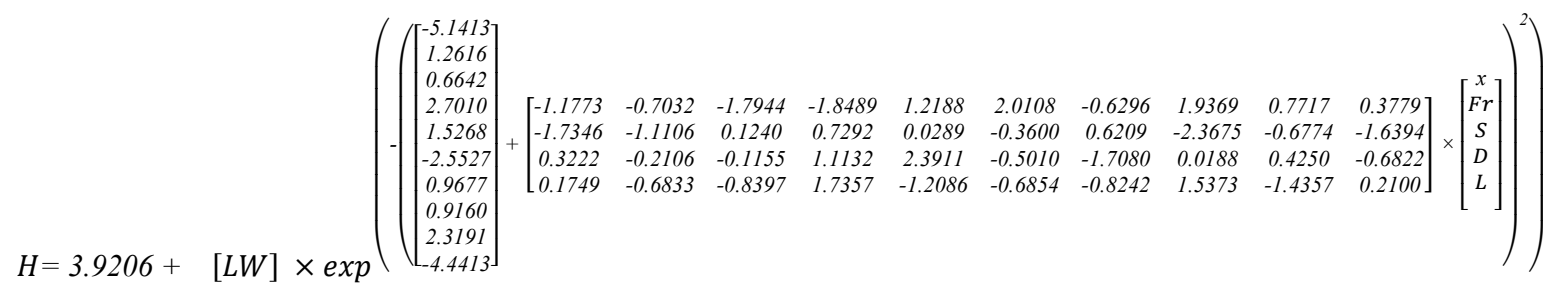

where $L W=\left[\begin{array}{ll}6.4552-2.1276 & 2.79847 .86254 .79084 .3514-6.4366-4.26002 .30874 .7381\end{array}\right]$, $H$ is hardness, $F r$ is feed rate, $S$ is spindle speed, $D$ is tool diameter, $L_{V}$ is viscosity of the lubricant, $C$ is the intercept, and Coeff is a coefficient.

Many different validation metrics are used for assessing and measuring the agreement between a predictive model and physical observations with the aim of selecting the best models or equations, and choosing the proper validation metric can be a crucial point and a challenge for evaluating results. In this study, the equations developed were compared and validated with the validation metrics listed in Table 9. In order to check the equations in question, different validation metrics were used to test performance on the basis of the results of the equations used in the hardness calculation. The criteria of validation consist in minimising error. To this end, Root Mean Square Error (RMSE) and Mean Absolute Error (MAE) were used for validation in this study. RMSE can be more sensitive to the error in case the MAE is more stable. However, RMSE and MAE are more accurate evaluation metrics compared to other metrics [57]. The equation's more reliable performance is guaranteed by a condition where MAE and RMSE values are close to 0 . Nevertheless, the large variance between RMSE and MAE values represents significant variations in error distribution. Consequently, Mean Relative Error (MRE) was used to measure the precision of the equations applied.

Table 9. Assessment of best alternative equations with different validation metrics for hardness calculation.

\begin{tabular}{|c|c|c|c|c|}
\hline Validation Metric & $\begin{array}{c}\text { Linear Cross-Validation } \\
\text { Regression }\end{array}$ & $\begin{array}{l}\text { Linear Cross-Validation } \\
\text { with Multiple } \\
\text { Regression of Viscosity }\end{array}$ & $\begin{array}{l}\text { Multiple } \\
\text { Regression }\end{array}$ & $\begin{array}{l}\text { Equation Based on } \\
\text { Biases and Weights }\end{array}$ \\
\hline Mean Error & 0.0000 & 0.0000 & -0.0002 & -0.0306 \\
\hline Mean Absolute Error & 4.8183 & 3.6826 & 2.7811 & 1.8954 \\
\hline Mean Square Error & 40.9419 & 29.2784 & 22.0436 & 20.2431 \\
\hline Root Mean Square Error & 6.3986 & 5.4110 & 4.6951 & 4.4992 \\
\hline Mean Relative Error & 0.0963 & 0.0727 & 0.0555 & 0.0367 \\
\hline Standard Deviation, $\sigma$ & 6.5955 & 5.5775 & 4.8396 & 4.6376 \\
\hline Standard Error of Mean & 1.5996 & 1.3527 & 1.1738 & 1.1248 \\
\hline
\end{tabular}

As can be seen in Table 9, the suggested Equation Based on Biases and Weight shows much greater reliability compared to other equations, and the next most reliable equation is the Multiple Regression equation. Consequently, both could be applied to precisely calculate the hardness of the SPIF component. Figure 10 illustrates the ability of the developed equations to precisely calculate the hardness of SPIF components compared to the real values of hardness. The fluctuating and uneven hardness in Figure 10 is normal because the values are for different components formed in various conditions using SPIF. All of the hardness data were used in predictions models; by sorting these data from low to high or vice versa will affect the random selection of data as training and testing values, which may make it challenging to distinguish the difference between the actual values of hardness and the predicted values by various models in the figure. The HV of points $1-4$ is related to the feed rate, $5-8$ is related to the spindle speed, $9-12$ is related to the tool diameter, and the rest is related to the four types of grease and one coolant oil. 
The significant change in the values is because these values were obtained from different components formed in various process conditions. The goal is to employ all of these data to derive different equations despite fluctuations in the data because the mentioned parameter will have parametric values that can be changed in the equations; in the end, the best equation is selected based on the predictive values of hardness that are closest to the actual values with minimum error.

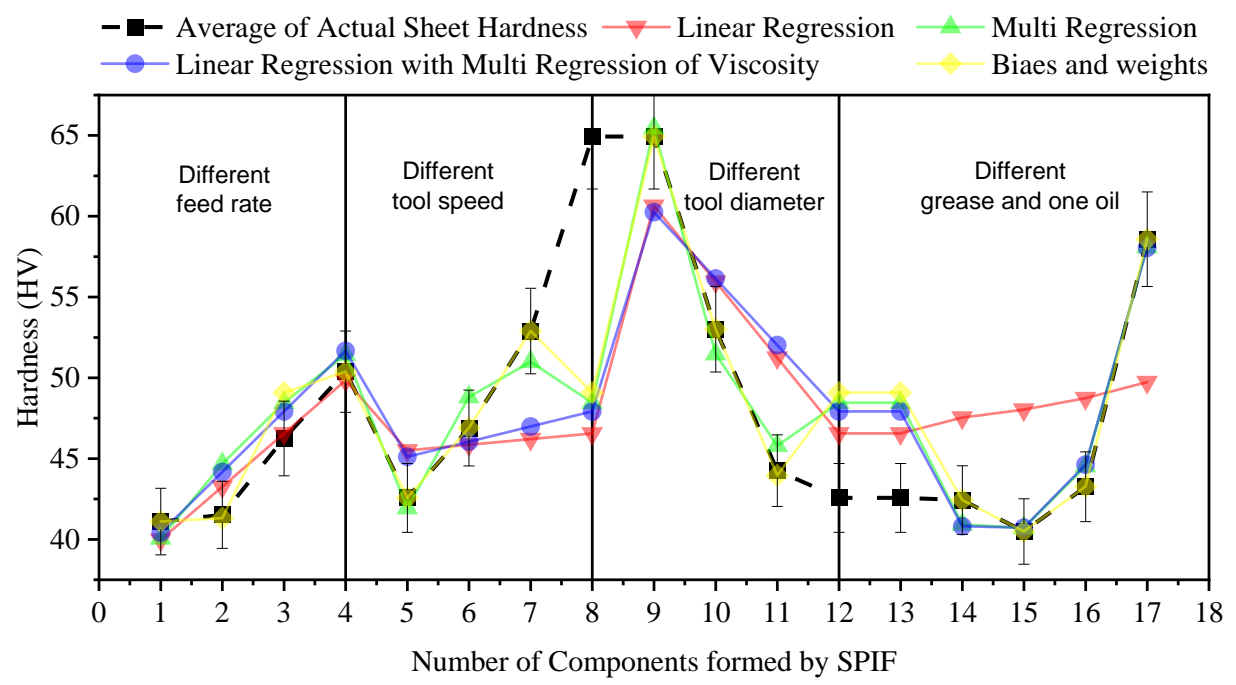

Figure 10. Calculated and real hardness of SPIF components.

The outcomes achieved via the proposed equations versus the real data are presented in Figure 11a-d. The solid line shows a hypothetical exact fit of actual and calculated hardness values, over which data are superimposed. Data dispersion and deviation are based on the ability of the selected equation to predict the hardness values with minimum errors; i.e., a large number of data points that do not match the approximate line (superimposed line) means high error, and a large number of points that match this line means lower error. A satisfactory agreement between the experimental and calculated values was observed for two equations, represented in Figure $11 \mathrm{c}$ and $\mathrm{d}$. This figure shows that the equations can appropriately estimate hardness. The connection between the calculated and real data reveals that the calculated values were in agreement with values from the real experiment.

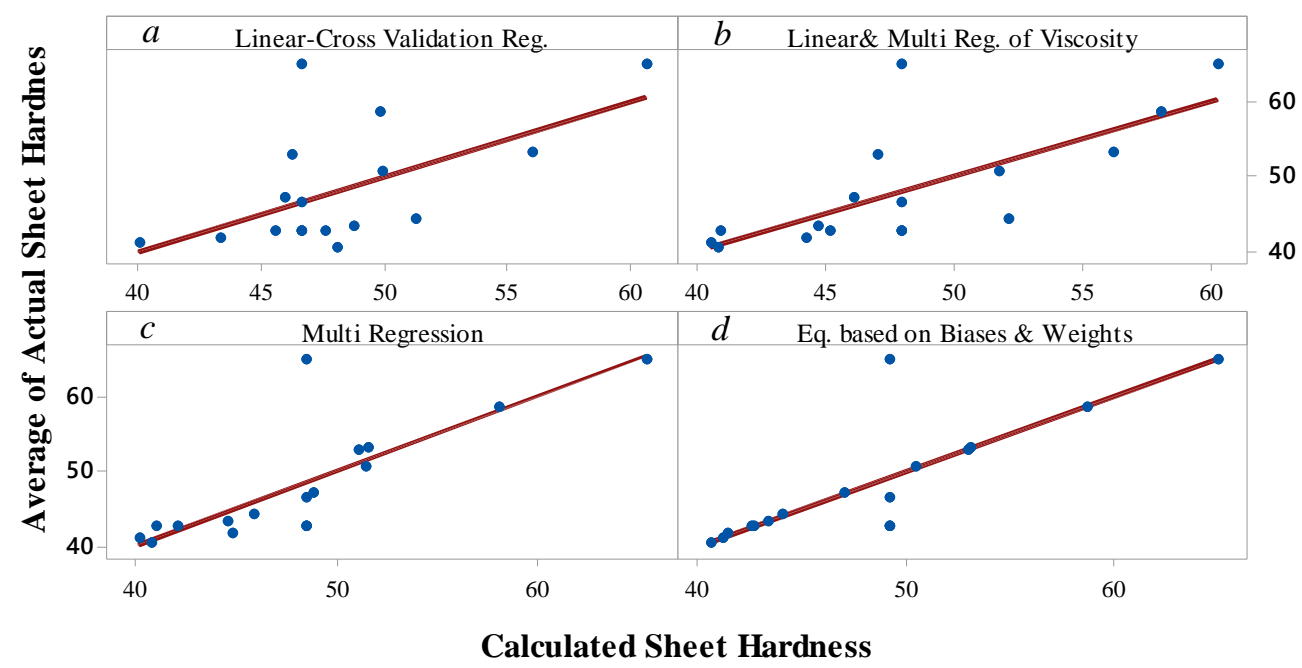

Figure 11. Actual and calculated values obtained with equations of (a) Linear Cross-Validation Regression, (b) Linear Cross-Validation with Multiple Regression of Viscosity, (c) Multiple Regression, and (d) Equation Based on Biases and Weights. 


\subsection{Contribution Analysis of Input Variables}

Various methods can be used to evaluate the contribution of each parameter individually and its effective rate on the output. To generate dependent variables, different algorithms for determining the RI of different parameters were employed in this study as a predictor of the predicted output, which is hardness. The algorithms used are Garson's algorithm [58] and the Most-Squares (MS) algorithm, which was proposed by Ibrahim [59]. The equations of the mentioned algorithms are defined in Equations (6) and (7). Both of the algorithms are based on the connection weights of the neurons of the ANN model, which was built for this purpose using MATLAB R2020a [60]. The network structures consist of input, hidden, and output layers, and the number of neurons is (4-10-1). As a mathematical tool for making predictions in machine learning for the purpose of training multilayer networks, a backpropagation learning algorithm was used: this algorithm is called "multilayer perceptron" (MLP), the concept of which was established by Werbos in 1974 and Rumelhart, McClelland, and Hinton in 1986 [61]. The Garson method has also been used in many studies, as presented in [62-67]. Goh [68] applied the Garson algorithm and claimed that RI estimation requires the partitioning of the hidden output weights into elements connected to each neuron in the input layers. Nevertheless, a comparative study of seven different algorithms included the above-mentioned methods to assess relative importance, as outlined in [59]. The author asserted that the Most-Squares method is a better method in comparison to the other methods, and the Most-Squares method seems to outperform all the other methods, as described by the equations below.

$$
\begin{gathered}
R I(\%)=\frac{\left[\sum_{j=1}^{n_{h}}\left(y_{v j} / \sum_{k=1}^{n_{v}} y_{k j}\right) h O_{j}\right]}{\sum_{y=1}^{n_{v}}\left[\sum_{j=1}^{n_{h}}\left(y_{v j} / \sum_{k=1}^{n_{v}} y_{k j}\right) h O_{j}\right]} \\
R I(\%)=\frac{\sum_{j=1}^{n_{v}}\left(y_{v j}^{i}-y_{v j}^{f}\right)^{2}}{\sum_{j=1}^{n_{v}} \sum_{v=1}^{n}\left(y_{v j}^{i}-y_{v j}^{f}\right)^{2}}
\end{gathered}
$$

where $n_{v}$ is the number of neurons in the input layer, $n_{h}$ is the number of neurons in the hidden layer, $y_{j}$ is the absolute value of connection weights between the input and the hidden layers, $h \mathrm{O}_{j}$ is the absolute value of connection weights between the hidden and the output layers, $\sum_{j=1}^{n_{v}}\left(y_{v j}^{i}-y_{v j}^{f}\right)^{2}$ is the sum squared difference between initial connection weights and final connection weights from the input layer to the hidden layer, and $\sum_{j=1}^{n_{v}} \sum_{v=1}^{n}\left(y_{v j}^{i}-y_{v j}^{f}\right)^{2}$ is the total of the sum squared difference of all inputs.

The replacement of the input parameters with greater RI significantly influences the outcomes as compared to changes in the parameters with lower RI values $[66,67,69]$. In the current study, the input parameters are the feed rate, spindle speed, tool diameter and different coolant oils, whereas the outcome is the hardness of the component formed using SPIF.

With regard to the relative importance and weights analysis, the most significant factor affecting hardness, as described in Figure 12a, is the feed rate with an RI of $31 \%$, followed by tool diameter with an RI of $25 \%$. Another interesting observation, based on Figure $12 b$, is a slight difference in the RI ratios. The tool diameter with an RI of $29 \%$ is the most influential factor on hardness, followed by feed rate with an RI of $28 \%$. Relying on the Garson method to assess the contribution, it can be claimed that spindle speed and viscosity have nearly the same RI, with values of $23 \%$ and $21 \%$, respectively. When the MS method was used, the relative importance of spindle speed and viscosity was $24 \%$ and $19 \%$, respectively, the values of which express the effects on hardness. Based on the above-mentioned facts, it can be asserted that the most significant parameters that jointly influence SPIF hardness are the feed rate and tool diameter. A slight difference is acceptable due to the difference in algorithms of the two methods and thanks to the small 
amount of data studied. It is worth mentioning that the Garson method partitions hidden output connection weights into components associated with each input neuron and uses absolute values of connection weights. At the same time, connection weights between the hidden and the output layers were not used in the MS method: instead, connection weights between the input and hidden layers were used.
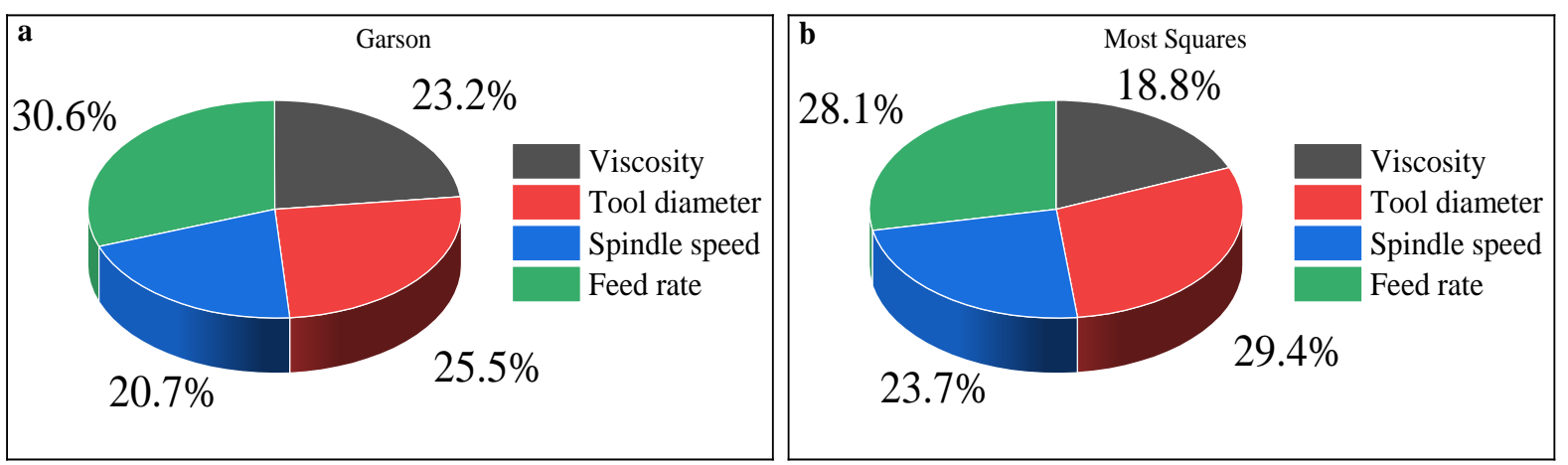

Figure 12. Relative importance of different input variables according to the (a) Garson and (b) Most-Squares algorithms.

\section{Conclusions}

In this study, the effects of four process parameters on hardness were investigated experimentally: the influences of feed rate, spindle speed, and tool diameter on hardness were successfully analysed. Regression equations were established using both linear and quadratic functions based on biases and weights generated from the ANN model of influential forming parameters. Two different methods of RI were used to assess the effects of SPIF parameters on outputs. The RI values of the Garson and Most-Squares methods revealed that feed rate and tool diameter are influential factors, impacting hardness by $29.5 \%$ and $27 \%$ on average, respectively. Based on our study, the effects of four parameters on hardness can be summarised as follows:

- An increase in the feed rate increases hardness when coolant oil is used. Hardness decreases when grease is used (which happens by way of filling the grooves between asperities with debris carried by the grease).

- The hardness of the component increases when tool speed increases.

- Increases in tool diameter result in a decrease in the hardness of components.

- Grease properties are certain to affect hardness values.

- The use of grease instead of coolant oil generates homogeneous hardness values at different points of the same formed sheet.

From the first four findings, it can be concluded that in order to increase the hardness of a SPIF component made of AA1100 aluminium alloy, high feed rates and high tool speed have to be applied, and coolant oil must be used instead of grease if tools smaller than $8 \mathrm{~mm}$ in diameter are used. A significant finding of the study is that the Biases and Weights-Based model, jointly used with Multiple Regression, yielded the best calculation of hardness. In the scope of the calculations, the results were assessed using different validation metrics; in the case of the above-mentioned models, the lowest MRE values were 0.0367 and 0.0555 , respectively.

\section{Recommendations for Further Research}

This research presented many issues that require further investigation. Given this, it is worth researching the impact of the studied parameters on sheets of different materials and thicknesses. It is essential to understand whether the mechanical properties of the forming tool affect the hardness of the components or not. A detailed study and evaluation of the different microstructures derived from the different processing conditions of the ISF process should be investigated to examine the impact of the parameters on the grain 
size, which affects the component hardness. In addition, based on the authors' knowledge, tool shape and tool material are vital parameters, and the hardness of formed components might be closely related to these parameters, which also merits investigation. Furthermore, different cases should be analysed with different parameter values to test and validate the developed regression equations.

Author Contributions: Conceptualisation, S.M.N., I.P. and S.A.N.; methodology, S.M.N., I.P., S.A.N., and Z.J.V.; formal analysis S.M.N., I.P., T.T., S.A.N., Z.J.V., and A.J.; investigation, S.M.N. and S.A.N.; data curation, S.M.N., I.P., and Z.J.V.; writing—original draft preparation, S.M.N.; writing—review and editing, S.M.N., I.P., and T.T.; supervision, I.P. and S.A.N.; project administration, I.P.; funding acquisition, S.M.N., I.P., and Z.J.V. All authors have read and agreed to the published version of the manuscript.

Funding: This research received no external funding.

Institutional Review Board Statement: Not applicable.

Informed Consent Statement: Not applicable.

Data Availability Statement: The data presented in this study are available on request from the corresponding author.

Acknowledgments: The research reported in this paper was supported by the National Laboratory of Artificial Intelligence funded by the NRDIO under the auspices of the Ministry for Innovation and Technology and by the European Commission through the H2020 project EPIC (https: / / www.centreepic.eu/) (accessed on 26 November 2021) under grant No. 739592. In addition, this research was supported by Hungary's TEMPUS Public Foundation and Stipendium Hungaricum Scholarship.

Conflicts of Interest: The authors declare no conflict of interest.

\section{References}

1. Trzepieciński, T.; Oleksik, V.; Pepelnjak, T.; Najm, S.M.; Paniti, I.; Maji, K. Emerging Trends in Single Point Incremental Sheet Forming of Lightweight Metals. Metals 2021, 11, 1188. [CrossRef]

2. Szpunar, M.; Ostrowski, R.; Trzepieciński, T.; Kaščák, L'. Central Composite Design Optimisation in Single Point Incremental Forming of Truncated Cones from Commercially Pure Titanium Grade 2 Sheet Metals. Materials 2021, 14, 3634. [CrossRef]

3. Trzepieciński, T.; Najm, S.M.; Sbayti, M.; Belhadjsalah, H.; Szpunar, M.; Lemu, H.G. New Advances and Future Possibilities in Forming Technology of Hybrid Metal-Polymer Composites Used in Aerospace Applications. J. Compos. Sci. 2021, 5, 217. [CrossRef]

4. Cooper, D.R.; Gutowski, T.G. Prospective Environmental Analyses of Emerging Technology: A Critique, a Proposed Methodology, and a Case Study on Incremental Sheet Forming. J. Ind. Ecol. 2020, 24, 38-51. [CrossRef]

5. Dittrich, M.A.; Cao, J.; Roth, J.T.; Xia, Z.C.; Kiridena, V.; Ren, F.; Henning, H.; Gutowski, T.G. Exergy analysis of incremental sheet forming. Prod. Eng. 2012, 6, 169-177. [CrossRef]

6. Ingarao, G.; Ambrogio, G.; Gagliardi, F.; Di Lorenzo, R. A sustainability point of view on sheet metal forming operations: Material wasting and energy consumption in incremental forming and stamping processes. J. Clean. Prod. 2012, 29-30, 255-268. [CrossRef]

7. Emmens, W.C.; Sebastiani, G.; van den Boogaard, A.H. The technology of Incremental Sheet Forming-A brief review of the history. J. Mater. Process. Technol. 2010, 210, 981-997. [CrossRef]

8. Li, Y.; Chen, X.; Liu, Z.; Sun, J.; Li, F.; Li, J.; Zhao, G. A review on the recent development of incremental sheet-forming process. Int. J. Adv. Manuf. Technol. 2017, 92, 2439-2462. [CrossRef]

9. Behera, A.K.; de Sousa, R.A.; Ingarao, G.; Oleksik, O. Single point incremental forming: An assessment of the progress and technology trends from 2005 to 2015. J. Manuf. Process. 2017, 27, 37-62. [CrossRef]

10. Raju, C.; Sathiya Narayanan, C. Application of a hybrid optimization technique in a multiple sheet single point incremental forming process. Measurement 2016, 78, 296-308. [CrossRef]

11. Kumar, A.; Gulati, V.; Kumar, P.; Singh, V.; Kumar, B.; Singh, H. Parametric effects on formability of AA2024-O aluminum alloy sheets in single point incremental forming. J. Mater. Res. Technol. 2019, 8, 1461-1469. [CrossRef]

12. Zavala, J.M.D.; Martínez-Romero, O.; Elías-Zúñiga, A.; Gutiérrez, H.M.L.; la Vega, A.E.; Taha-Tijerina, J. Study of Friction and Wear Effects in Aluminum Parts Manufactured via Single Point Incremental Forming Process Using Petroleum and Vegetable Oil-Based Lubricants. Materials 2021, 14, 3973. [CrossRef]

13. Najm, S.M.; Paniti, I. Study on Effecting Parameters of Flat and Hemispherical end Tools in SPIF of Aluminium Foils. Teh. Vjesn.-Tech. Gaz. 2020, 27, 1844-1849. [CrossRef]

14. Najm, S.M.; Paniti, I. Experimental Investigation on the Single Point Incremental Forming of AlMn1Mg1 Foils using Flat End Tools. IOP Conf. Ser. Mater. Sci. Eng. 2018, 448, 012032. [CrossRef] 
15. Paniti, I. Adaptation of Incremental Sheet Forming into cloud manufacturing. CIRP J. Manuf. Sci. Technol. 2014, 7, 185-190. [CrossRef]

16. Fratini, L.; Ambrogio, G.; Di Lorenzo, R.; Filice, L.; Micari, F. Influence of mechanical properties of the sheet material on formability in single point incremental forming. CIRP Ann. 2004, 53, 207-210. [CrossRef]

17. Zhang, S.; Tang, G.H.; Wang, W.; Jiang, X. Evaluation and optimization on the formability of an AZ31B Mg alloy during warm incremental sheet forming assisted with oil bath heating. Measurement 2020, 157, 107673. [CrossRef]

18. Liu, Z.; Li, Y.; Meehan, P.A. Experimental investigation of mechanical properties, formability and force measurement for AA7075-O aluminum alloy sheets formed by incremental forming. Int. J. Precis. Eng. Manuf. 2013, 14, 1891-1899. [CrossRef]

19. Li, Y.; Chen, X.; Zhai, W.; Wang, L.; Li, J.; Guoqun, Z. Effects of process parameters on thickness thinning and mechanical properties of the formed parts in incremental sheet forming. Int. J. Adv. Manuf. Technol. 2018, 98, 3071-3080. [CrossRef]

20. Manco, L.; Filice, L.; Ambrogio, G. Analysis of the thickness distribution varying tool trajectory in single-point incremental forming. Proc. Inst. Mech. Eng. Part B J. Eng. Manuf. 2011, 225, 348-356. [CrossRef]

21. Krasowski, B.; Kubit, A.; Trzepieciński, T.; Slota, J. Experimental Analysis of Single Point Incremental Forming of Truncated Cones in DC04 Steel Sheet. Adv. Mater. Sci. 2020, 20, 5-15. [CrossRef]

22. Zain, A.M.; Haron, H.; Sharif, S. Prediction of surface roughness in the end milling machining using Artificial Neural Network. Expert Syst. Appl. 2010, 37, 1755-1768. [CrossRef]

23. Amirjan, M.; Khorsand, H.; Siadati, M.H.; Eslami Farsani, R. Artificial Neural Network prediction of Cu-Al2O3 composite properties prepared by powder metallurgy method. J. Mater. Res. Technol. 2013, 2, 351-355. [CrossRef]

24. Ezugwu, E.O.; Fadare, D.A.; Bonney, J.; Da Silva, R.B.; Sales, W.F. Modelling the correlation between cutting and process parameters in high-speed machining of Inconel 718 alloy using an artificial neural network. Int. J. Mach. Tools Manuf. 2005, 45, 1375-1385. [CrossRef]

25. Li, E. Reduction of springback by intelligent sampling-based LSSVR metamodel-based optimization. Int. J. Mater. Form. 2013, 6, 103-114. [CrossRef]

26. Marouani, H.; Aguir, H. Identification of material parameters of the Gurson-Tvergaard-Needleman damage law by combined experimental, numerical sheet metal blanking techniques and artificial neural networks approach. Int. J. Mater. Form. 2012, 5 , 147-155. [CrossRef]

27. Lela, B.; Bajić, D.; Jozić, S. Regression analysis, support vector machines, and Bayesian neural network approaches to modeling surface roughness in face milling. Int. J. Adv. Manuf. Technol. 2009, 42, 1082-1088. [CrossRef]

28. Hussaini, S.M.; Singh, S.K.; Gupta, A.K. Experimental and numerical investigation of formability for austenitic stainless steel 316 at elevated temperatures. J. Mater. Res. Technol. 2014, 3, 17-24. [CrossRef]

29. Kondayya, D.; Gopala Krishna, A. An integrated evolutionary approach for modelling and optimization of laser beam cutting process. Int. J. Adv. Manuf. Technol. 2013, 65, 259-274. [CrossRef]

30. Trzepieciński, T.; Kubit, A.; Dzierwa, A.; Krasowski, B.; Jurczak, W. Surface Finish Analysis in Single Point Incremental Sheet Forming of Rib-Stiffened 2024-T3 and 7075-T6 Alclad Aluminium Alloy Panels. Materials 2021, 14, 1640. [CrossRef] [PubMed]

31. Najm, S.M.; Paniti, I. Artificial neural network for modeling and investigating the effects of forming tool characteristics on the accuracy and formability of thin aluminum alloy blanks when using SPIF. Int. J. Adv. Manuf. Technol. 2021, 114, $2591-2615$. [CrossRef]

32. Najm, S.M.; Paniti, I. Predict the Effects of Forming Tool Characteristics on Surface Roughness of Aluminum Foil Components Formed by SPIF Using ANN and SVR. Int. J. Precis. Eng. Manuf. 2021, 22, 13-26. [CrossRef]

33. Baruah, A.; Pandivelan, C.; Jeevanantham, A.K. Optimization of AA5052 in incremental sheet forming using grey relational analysis. Measurement 2017, 106, 95-100. [CrossRef]

34. Kumar, A.; Gulati, V. Experimental investigations and optimization of forming force in incremental sheet forming. Sādhanā 2018, 43, 159. [CrossRef]

35. Kumar, A.; Gulati, V. Experimental investigation and optimization of surface roughness in negative incremental forming. Measurement 2019, 131, 419-430. [CrossRef]

36. Al-Attaby, Q.M.D.; Abaas, T.F.; Bedan, A.S. The Effect of Tool Path Strategy on Mechanical Properties of Brass (65-35) in Single Point Incremental Sheet Metal Forming (SPIF). J. Eng. 2013, 19, 629-637.

37. Mostafanezhad, H.; Menghari, H.G.; Esmaeili, S.; Shirkharkolaee, E.M. Optimization of two-point incremental forming process of AA1050 through response surface methodology. Measurement 2018, 127, 21-28. [CrossRef]

38. Premkumar, R.; Vignesh, R.V.; Padmanaban, R.; Govindaraju, M.; Santhi, R. Investigation on the microstructure, microhardness, and tribological behavior of AA1100-hBN surface composite. Koroze A Ochr. Mater. 2021, 65, 1-11. [CrossRef]

39. Song, X.; Zhang, J.; Zhai, W.; Taureza, M.; Castagne, S.; Danno, A. Numerical and experimental investigation on the deformation mechanism of micro single point incremental forming process. J. Manuf. Process. 2018, 36, 248-254. [CrossRef]

40. Kaufman, J.G. Applications for aluminum alloys and tempers. In Introduction to Aluminum Alloys and Tempers; ASM International: Materials Park, OH, USA, 2000; Volume 1100, p. 242.

41. Alcotec.com. Understanding the Alloys of Aluminum. 2021. Available online: http://www.alcotec.com/us/en/education/ knowledge/techknowledge/understanding-the-alloys-of-aluminum.cfm (accessed on 19 November 2021).

42. Training, A.; Maintenance, B.; Schools, A.; Books, A.; Jar, T.; Repair, A. Aluminum Alloys. Flight-Mechanic.com. 2021. Available online: https:/ / www.flight-mechanic.com/aluminum-alloys/ (accessed on 19 November 2021). 
43. Davis, J.R. Aluminum and Aluminum Alloys; ASM Int.: Materials Park, OH, USA, 2001; pp. 351-416. [CrossRef]

44. Committee, A.I.H. ASM Handbook Volume 2: Properties and Selection: Nonferrous Alloys and Special-Purpose Materials; ASM International: Materials Park, OH, USA, 1990.

45. Kumar, A.; Gulati, V. Optimization and investigation of process parameters in single point incremental forming. Indian J. Eng. Mater. Sci. 2020, 27, 246-255.

46. Skjoedt, M.; Hancock, M.H.; Bay, N. Creating Helical Tool Paths for Single Point Incremental Forming. Key Eng. Mater. 2007, 344, 583-590. [CrossRef]

47. United States Environmental Protection Agency; Office of Wastewater Management Washington. Environmentally Acceptable Lubricants. In Encyclopedia of Lubricants and Lubrication; Springer: Berlin/Heidelberg, Germany, 2014; p. 526.

48. IS0 3448:1992(E). Industrial Liquid Lubricants_IS0 Viscosity Classification; International Organization for Standardization: Geneva, Switzerland, 1992.

49. Syahrullail, S.; Kamitani, S.; Shakirin, A. Performance of Vegetable Oil as Lubricant in Extreme Pressure Condition. Procedia Eng. 2013, 68, 172-177. [CrossRef]

50. Diabb, J.; Rodríguez, C.A.; Mamidi, N.; Sandoval, J.A.; Taha-Tijerina, J.; Martínez-Romero, O.; Elías-Zúñiga, A. Study of lubrication and wear in single point incremental sheet forming (SPIF) process using vegetable oil nanolubricants. Wear 2017, 376-377, 777-785. [CrossRef]

51. Nama, S.A.; Namer, N.S.M.; Najm, S.M. The Effect of using Grease on the Surface Roughness of Aluminum 1100 Sheet during the Single Point Incremental Forming Process. J. Trends Mach. Des. 2014, 1, 53-56.

52. Kim, Y.; Park, J. Effect of process parameters on formability in incremental forming of sheet metal. J. Mater. Process. Technol. 2002, 130, 42-46. [CrossRef]

53. Hol, J.; Meinders, V.T.; Geijselaers, H.J.M.; Van Den Boogaard, A.H. Multi-scale friction modeling for sheet metal forming: The mixed lubrication regime. Tribol. Int. 2015, 85, 10-25. [CrossRef]

54. McAnulty, T.; Jeswiet, J.; Doolan, M. Formability in single point incremental forming: A comparative analysis of the state of the art. CIRP J. Manuf. Sci. Technol. 2017, 16, 43-54. [CrossRef]

55. Asgari, A.; Sedighi, M.; Riahi, M. Investigation of Punching Parameters Effect on Mechanical Properties of Al-1100-O in Incremental Sheet Metal Hammering Process. Strength Mater. 2015, 47, 882-889. [CrossRef]

56. Shrivastava, P.; Tandon, P. Investigation of the Effect of Grain Size on Forming Forces in Single Point Incremental Sheet Forming. Procedia Manuf. 2015, 2, 41-45. [CrossRef]

57. Misra, S.; He, J. Stacked neural network architecture to model the multifrequency conductivity/permittivity responses of subsurface shale formations. In Machine Learning for Subsurface Characterization, 1st ed.; Misra, S., Li, H., He, J., Eds.; Elsevier Inc.: Amsterdam, The Netherlands, 2020; pp. 103-127.

58. Garson, G.D. Interpreting Neural-Network Connection Weights. AI Expert 1991, 6, 46-51.

59. Ibrahim, O.M. A comparison of methods for assessing the relative importance of input variables in artificial neural networks. J. Appl. Sci. Res. 2013, 9, 5692-5700.

60. Beale, M.H.; Hagan, M.; Demuth, H. Deep Learning Toolbox Getting Started Guide. In Deep Learn. Toolbox; The MathWorks Inc.: Natick, MA, USA, 2019. [CrossRef]

61. Riedmiller, P.M. Machine Learning: Multi Layer Perceptrons. Albert-Ludwigs-University Freibg. AG Maschinelles Lernen. Available online: http:/ / ml.informatik.uni-freiburg.de/_media/documents/teaching/ss09/ml/mlps.pdf (accessed on 10 October 2021).

62. Zarei, M.J.; Ansari, H.R.; Keshavarz, P.; Zerafat, M.M. Prediction of pool boiling heat transfer coefficient for various nanorefrigerants utilizing artificial neural networks. J. Therm. Anal. Calorim. 2020, 139, 3757-3768. [CrossRef]

63. Ding, H.; Luo, W.; Yu, Y.; Chen, B. Construction of a Robust Cofactor Self-Sufficient Bienzyme Biocatalytic System for Dye Decolorization and its Mathematical Modeling. Int. J. Mol. Sci. 2019, 20, 6104. [CrossRef] [PubMed]

64. Zhou, B.; Vogt, R.D.; Lu, X.; Xu, C.; Zhu, L.; Shao, X.; Liu, H.; Xing, M. Relative Importance Analysis of a Refined Multi-parameter Phosphorus Index Employed in a Strongly Agriculturally Influenced Watershed. Water Air Soil Pollut. 2015, 226, 25. [CrossRef]

65. Shabanzadeh, P.; Yusof, R.; Shameli, K. Artificial neural network for modeling the size of silver nanoparticles' prepared in montmorillonite/starch bionanocomposites. J. Ind. Eng. Chem. 2015, 24, 42-50. [CrossRef]

66. Vatankhah, E.; Semnani, D.; Prabhakaran, M.P.; Tadayon, M.; Razavi, S.; Ramakrishna, S. Artificial neural network for modeling the elastic modulus of electrospun polycaprolactone/gelatin scaffolds. Acta Biomater. 2014, 10, 709-721. [CrossRef]

67. Rezakazemi, M.; Razavi, S.; Mohammadi, T.; Nazari, A.G. Simulation and determination of optimum conditions of pervaporative dehydration of isopropanol process using synthesized PVA-APTEOS/TEOS nanocomposite membranes by means of expert systems. J. Memb. Sci. 2011, 379, 224-232. [CrossRef]

68. Goh, A.T.C. Back-propagation neural networks for modeling complex systems. Artif. Intell. Eng. 1995, 9, 143-151. [CrossRef]

69. Nabipour, M.; Keshavarz, P. Modeling surface tension of pure refrigerants using feed-forward back-propagation neural networks. Int. J. Refrig. 2017, 75, 217-227. [CrossRef] 